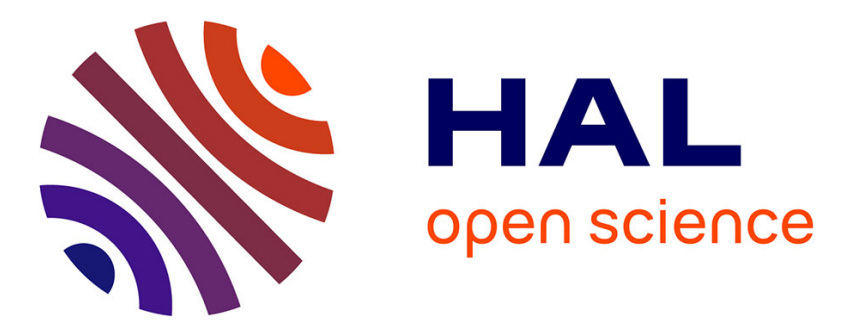

\title{
ELECTRON DRIFT MOBILITY MEASUREMENT IN UNDOPED TRIODE DC SPUTTERED a-Si : $H$
}

\author{
Jean Peyré, J. Baixeras, D. Mencaraglia, P. Andro, C. Longeaud
}

\section{To cite this version:}

Jean Peyré, J. Baixeras, D. Mencaraglia, P. Andro, C. Longeaud. ELECTRON DRIFT MOBILITY MEASUREMENT IN UNDOPED TRIODE DC SPUTTERED a-Si: H. Journal de Physique Colloques, 1981, 42 (C4), pp.C4-163-C4-166. 10.1051/jphyscol:1981433 . jpa-00220889

\section{HAL Id: jpa-00220889 https://hal.science/jpa-00220889}

Submitted on 1 Jan 1981

HAL is a multi-disciplinary open access archive for the deposit and dissemination of scientific research documents, whether they are published or not. The documents may come from teaching and research institutions in France or abroad, or from public or private research centers.
L'archive ouverte pluridisciplinaire HAL, est destinée au dépôt et à la diffusion de documents scientifiques de niveau recherche, publiés ou non, émanant des établissements d'enseignement et de recherche français ou étrangers, des laboratoires publics ou privés. 


\title{
ELECTRON DRIFT MOBILITY MEASUREMENT IN UNDOPED TRIODE DC SPUTTERED
} a-Si:H

\author{
J.F. Peyre, J. Baixeras, D. Mencaraglia, P. Andro and C. Longeaud \\ L.G.E.P. - E.S.E., Laboratoire associé au CNRS n¹27, PZateau du MouZon, \\ 91190 Gif-sur-Yvette, France
}

The first measurements of electron drift mobility in amorphous silicon were carried out on undoped glow discharge a Si-H by Le Comber et al (1) who used a time of flight technique with carrier injection by an electron beam. More recently different authors ( 2 - 6 ) applied this technique for electron and hole drift mobility measurements in undoped or doped glow discharge a Si-H. In a recent work, Tiedje et $a l$. ( 7 ) reported direct measurement of the electron drift mobility in RF sputtered $a \mathrm{Si}-\mathrm{H}$. They observed a dispersive transport in this material and measured a room temperature mobility of $0.05 \mathrm{~cm}^{2} \cdot \mathrm{v}^{-1} \cdot \mathrm{s}^{-1}$ (applied field of $5.10^{4} \mathrm{~V} \cdot \mathrm{cm}^{-1}$ ). In this paper, we report some time of flight measurements in undoped DC sputtered a Si-H and we present a theoretical model in order to explain the experimental results and to determine the electron drift mobility.

The films [ $\sim 1 \mu \mathrm{m}$ thick] were deposited by triode DC sputtering of an "electronic grade" monocrystalline silicon target; the plasma was formed by a mixture of 1 OmTorr of $A$ and 1 mTorr of $\mathrm{H}_{2}$. The substrates were heated to $550 \mathrm{~K}$ and the deposition rate was $3 \mathrm{~A} \cdot \mathrm{s}^{-1}$.

The investigated samples are "semi-transparent Pt/aSi-Hi/Cr-Sb" sandwich structures ; the evaporated $P$ l layer forming a Schottky contact. Electron-hole pairs are photogenerated at this contact by a short flash $(\simeq 30 \mathrm{nS})$ of blue light, delivered by a continous Argon ion laser coupled with an acousto-optic modulator. The absorption length at the $488 \mathrm{~nm}$ wavelength light was about $0.1 \mu \mathrm{m}(8)$. The electrons are swept accross the film by a DC constant voltage or by a square bias pulse adjusted so as to be longer than the transit time and shorter than the dielectric relaxation time of the material $[\simeq 100 \mu \mathrm{s}$ in the dark at room temperature $]$. The experimental set-up is shown in Fig. 1.

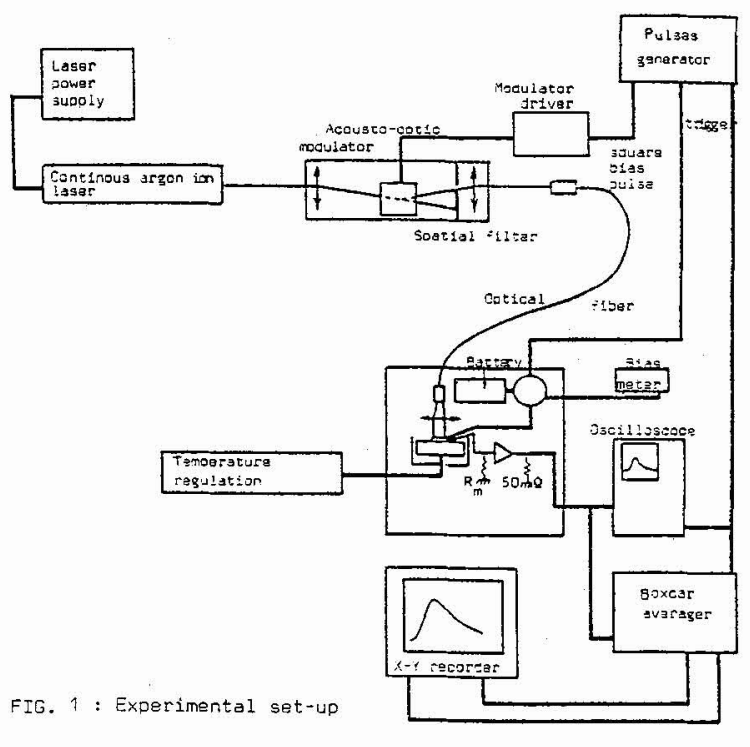

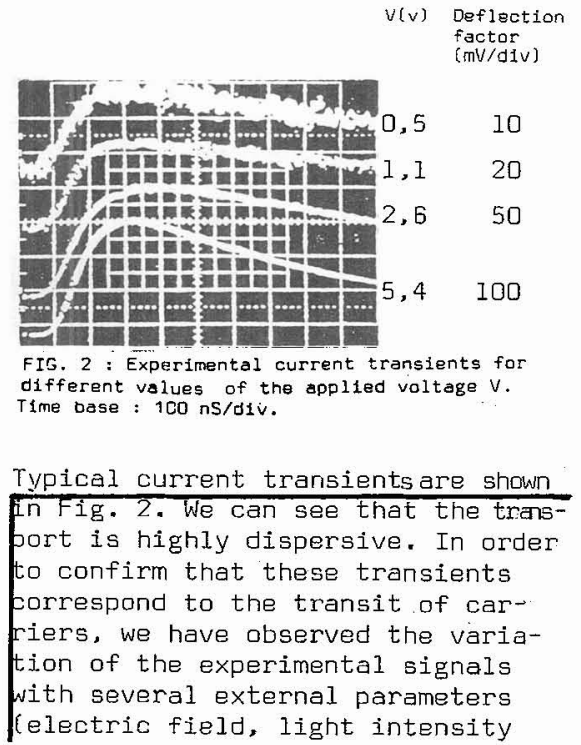


and wavelengthl. These variations are the expected ones and confirm clearly that the transient correspond to the transit. For instance, we can see in Fig. 2 that within the accuracy of measurements, the signal amplitude is proportional to the electric field, and that the falling time of the signal decreases with increasing electric field. As the transport is dispersive, we first tried to analyog our results using Scheer and Montroll theory ( 9 ). This gave us ambiguous results. Indeed, in most samples, a log-log plot of current as a function of time did not yield the two expec ted straight lines. For a few samples, this method allowed us to define a transit time, however in such cases the drift mobility dependence with the electric field was not that predicted by the theory. In view of this, we have carried out a numerical simulation of the transit. The aim of this simulation is : il to separate the role of the various mechanisms occuring simultaneously during the transit, iij to. emphasize which major mechanisms are responsible for the observed waveforms, iii) to derive a method for the determination of the electron drift mobility.

The simulation program solves the transport equations for the carriens, the current being given by (10)

$$
\begin{gathered}
j(t)=j(0)+\Delta j(t) \\
\Delta j(t)=\frac{\sigma_{0}}{L}[V(t)-v(0)]+\frac{q \Delta x}{L_{D}} \sum_{i=1}^{100}\left[\Delta n\left(x_{i}, t\right) \mu_{n}+\Delta p\left(x_{i}, t\right) \mu_{p}\right] E\left(x_{i}, t\right)+ \\
+q \frac{D_{n}}{L}\left[\Delta n(L, t)-\Delta n\left(x_{1}, t\right)\right]-q \frac{D}{L}\left[\Delta p(L, t)-\Delta p\left(x_{1}, t\right)\right]+\frac{E}{L} \frac{\partial v(t)}{\partial t}
\end{gathered}
$$

$V(t)$ is the potential drop accross the sample, $j(0)$ is the stationary current before the laser pulse, $\Delta \mathrm{n}$ and $\Delta \mathrm{p}$ are the increase of electrons and holes densities due to photogeneration. The sample thickness $L^{\prime}$ is divided into one hundred equal slices $\Delta \times\left(x_{i}\right.$ is the $i$ th slice, $\left.1 \leq i \leq 100\right) ; \Delta n$ and $\Delta p$ are calculated into each slice after each time increment using a step by step method and the form $\Delta j(t)$ of the current transient is obtained. We have carried out various calculations taking into account successively the main phenomenons able to disturb the transit of carriers i.e diffusion, recombination, distorsion of the electric field,finite penetration of the light, trapping, etc... We give here only the simulated curves the more similar to the experimental ones. For the simulated curves presented here, the electrons drift mobility has been choosen ten to hundred times greater than the holes drift mobility so, in general holes play no important role.

We first present the curves obtained when considering diffusion and direct recombination processes. The curves of Fig. 3 have been obtained for different values of the direct recombination coefficient, the electron diffusion coefficient being constant and equal to $10^{-4} \mathrm{~cm}^{2} \cdot \mathrm{s}^{-1}$. The coefficient of direct recombination $\gamma$ is introduced by means of the differential equation giving the variation rate of the free electrons density due to direct recombination i.e.

$$
\frac{\partial n(x, t)}{\partial t}=-\gamma\left[n(x, t) \cdot p(x, t)-n_{0} \cdot p_{0}\right]
$$

For the lowest values of $\gamma$; the form of the curves is close to that typical of diffusion only. On the other hend, for the highest value of $\gamma$, an expected deformation occurs at the beginning of the transit (when the two types of carriers are not yet well separated) and also during all the transit. So when direct recombination is the

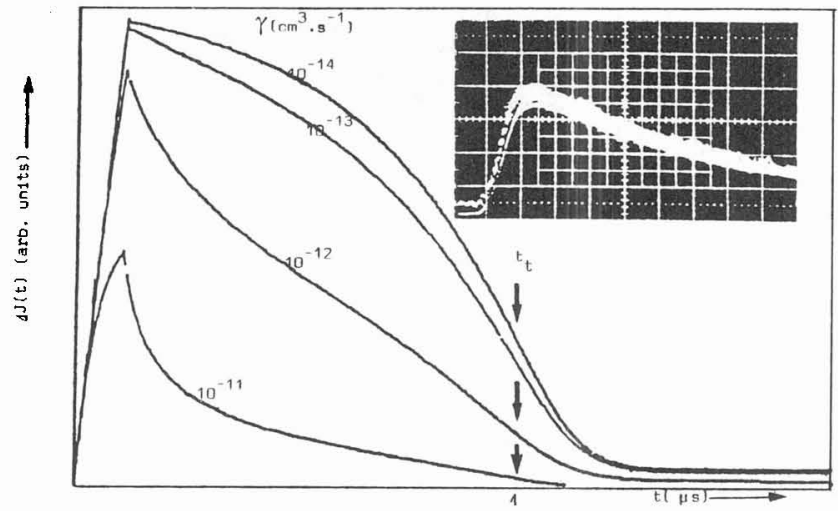

FIG 3 : Simulated curves for ellfferent values of the direct recombination coefficient and for a diffusion coefficient $0_{n}=10^{-4} \mathrm{~cm}^{2} \cdot \mathrm{s}^{-1}$. Insert : experimental current transients at 50,300 and $600 \mathrm{ml}$ of laser light power the vertical deflection factor has been varied for the comparison of the three curves\}.

main mechanism, the theory
predicts that the shape, and
not only the amplitude, of
the current transient should
be sensitive to a variation
of light intensity ; at least
at the beginning of the


transit when the two types of excess carriers coexist. In the experience, we have varied the light power of the laser in a range from $60 \mathrm{mw}$ to $600 \mathrm{mw}$, without any correlative variation of the form of the curves as can be seen in the insert of Fig. 3. So, we can conclude that an important direct recombination does not correspond to our experimental conditions. We have shown elsewhere (10) that diffusion neither plays a dominant role in the experimental curves.

Indirect recombination may also disturb the transit when the Iifetime of free electrons is much shorter than the transit time. However, if indirect recombination was responsible for the experimentally observed waveforms, a variation of the applied bias should not modify the tail of the experimental curves, completely imposed by the lifetime. The experimental behaviour is opposite to this prediction (cf. Fig. 2), so we conclude that indirect recombination does not correspond to our experimental situation.

We present now some results concerning trapping effects. In the simulation program, these processes are introduced by means of the differential equation giving the variation rate of the free electrons density due to trapping effects i.e

$$
\frac{\partial n(x, t)}{\partial t}=-\frac{\Delta n(x, t)}{\tau_{n}}+\frac{n^{\prime}(x, t)}{\tau_{n}^{\prime}}
$$

where $\tau_{n}$ is the trapping time constant; $n^{\prime}(x, t)$ is the density of trapped carriers at $x$, at time $t$ and $\tau^{\prime} n$ is the release time constant. A significant feature of the experimental curves is that the rising time of the current transients is much longer than the flash duration (cf. Fig. 2). This led us to suppose that all the photogenerated carriers were immediately trapped and then could be slowly released. Two main situations may occur : i] carriers are released with a given time constant and cannot be trapped again (this corresponds to $\boldsymbol{\tau}_{n}$ infinite). If the absorption length is small enough compared with the sample thickness, this situation can represent traps situated near the surface. ii) released carriers can be trapped again during their transit. This can correspond to a bulk repartition of traps in addition to surface traps. In both cases, when $\tau^{\prime} n$ is of the order or greater than the transit time of an ideally free electron, the aspect of the simulated curves is very similar to the experimental ones. However, in the first case the variation of the time of the maximum ( $t_{\text {max }}$ ) as a function of the bias does not correspond to that experimentally observed. On the other hand, in the second case, the variation of $t_{\text {max }}$ with bias is the same as the experimental one. An example of this case is presented in Fig. 4 where the simulated curves corresponding to four different values of the bias are shown. The corresponding transit timesare marked by arrows and reported in the insert. The time constants $\boldsymbol{\tau}_{\mathrm{n}}$ and $\boldsymbol{\tau}$ 'n are respectively 0.2 and $3 \mu \mathrm{s}$.

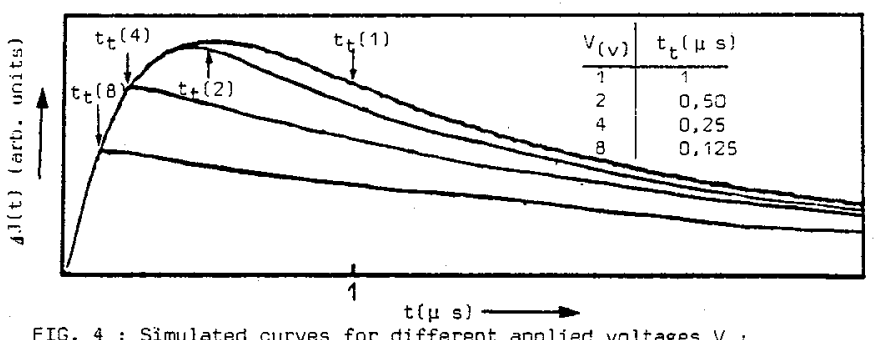

FIG. 4 : Simulated curves for different applied valtages $V$ $\tau_{n}=0,2$ us, $\tau_{n}^{\prime}=3$ us.

The corresponding variations of the reciprocal of $t_{\max }\left(t_{\max }{ }^{-1}\right)$ and of the transit time $\left(t_{t}{ }^{-1}\right)$ with the applied biss are reported in fig. 5. The experimentally observed field dependence of $t_{\max }$ is shown in Fig. 6, for the curves of Fig. 2 . As it has been noticed above. Fig. 5 and Fig. 6 show that the variations of $t_{\max }-1$ with the applied bias for the simulated (case ii) and experimental curves are very similar. In view of this, we conclude that the main mechanisms responsible for the experimen- 


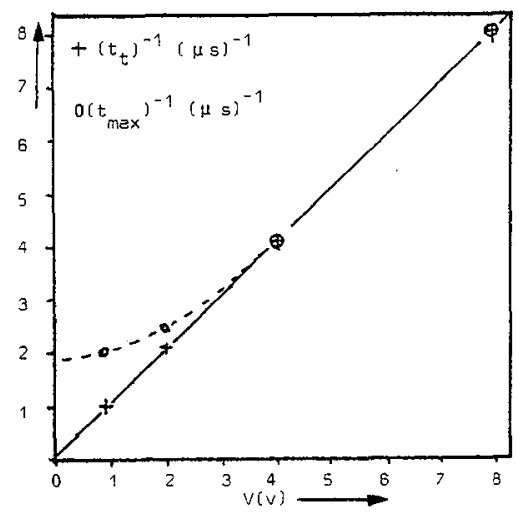

FIG. 5 : Voltage dependence of $t_{\max }$ and $t_{t}$ for the simulated curves of Fig. 4 .

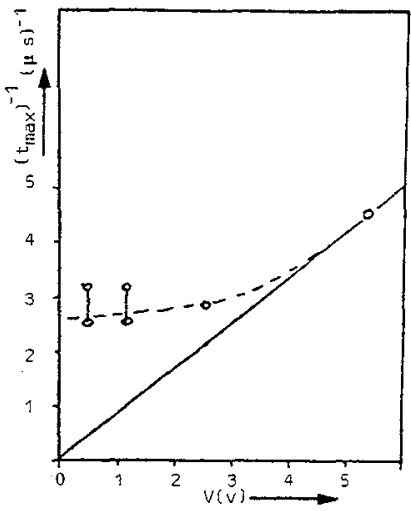

FIG. 6 : voltage dependence of $t_{\text {max }}$ for the experimental curves of Fig. 2 .

-tally observed waveforms are trapping and detrapping processes like those used in the simulation of Fig. 4. With this hypothesis, we are able to derive a method for the determination of the electron drift mobility : for the simulated curves, $t_{\max }$ is rather different from $t_{t}$ for the low values of the applied voltage; but when the bias is high enough $(\geq 4 \mathrm{~V}$ in Fig. 5) the plots of $t_{\max }{ }^{-1}$ and $t_{t}{ }^{-1}$ are superimposed. So, as $t_{t}{ }^{-1}$ is given by

$t_{t}{ }^{-1}=\mu V / L^{2}$, it is possible to derive the electron drift mobility from the slope of the straight Iine corresponding to the variation of $t_{\max }{ }^{-1}$ versus $V$ for the high values of $V$. Applying this method to the experimental results of Fig. 6, we obtain an approximative value of the electron drift mobility $\mu_{n}=0.8 .10^{-2} \mathrm{~cm}^{2} \mathrm{~V}^{-1} \mathrm{~s}^{-1}$. It is noworthy that this mobility can be either the true mobility of the free carriers, either a shallow trap-controlied mobility.

As a final support of the importance of trapping processes, one can notice that measurements were also made with uniformly observed red light in addition of the laser pulse and this led toadifferent shape of the observed waveforms. This fact may be interpreted by trapsfiling with the uniformly absorbed light.

In summary, we have shown that time of flight measurement in undoped triode DC sputtered a-SiH led to current transients typical of dispersive transport. The dispersive transport theory, used by several authors giving ambiguous results, we have carried aut a numerical simulation of the electronic transport. So, we could conclude that the main mechanisms responsible for the observed transit shape are trapping and detrapping processes with characteristic times of the order of the transit time $t_{t}$ of an ideally free electron.

In view of the simulation results, the time of flight $t_{t}$ is equal to the time of the maximum of the signal, when it is shorter than the trapping time constant $i . e$ when the applied field is high enough. In these conditions, the room temperature electron drift mobility is $0.8 \times 10^{-2} \mathrm{~cm}^{2} . \mathrm{v}^{-1} . \mathrm{s}^{-1}$.

This analysis should be completed now by the study of the dependence of the so-derived mobility with the temperature and for samples prepared under various conditions.

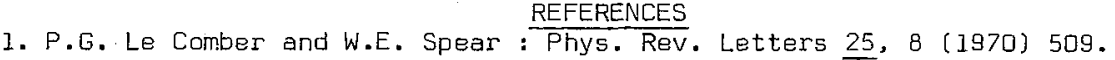

2. P.G. Le Comber, A. Madan and W.E. Spear : J. of Non-Cryst. Sol. 11 (1972) 219.

3. D. Allan, P.G. Le Comber and W.E. Spear : Amorphous and liquid semiconductors, Proc. of the Edinburgh Conf. ed. by W.E. Spear (Inst. of Phys. London(1977)p.323.

4. A.R. Moore : Applied Phys. Lett. 31, 11 (1977) 762.

5. D. Allan : Phil. Magazine B, 38, $\overline{4}$ [1978) 381.

6. W. Fuhs, M. Millevilie and J. Stuke : Phys. Stat. Sol. (b) 89 (1978) 495.

7. T. Tiedje, B. Abeles, D.L. Morel, T.D. Moustakas and C.R. Wronski : Appl. Phys. Lett. $36,8(1980), 695$.

8. J. Baixeras, M. Yacine, D. Mencaraglia and $P$. Andro : 2ème Colloque Internat. d'Energie Solaire, Barcelone (8-9 Mars 1979).

9. H. Scher and E.W. Montrol1 : Phys. Rev. B 12, 8 (1975) 2455.

10. J.F. Peyre.: "Docteur-Ingénieur" Degree obtained in Sept. 1980 at the University P. et M. Curie (PARIS VI). 